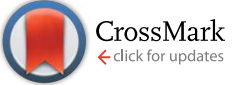

Cite this: RSC Adv., 2017, 7, 2466

\title{
Anti-cancer effects of torulene, isolated from Sporidiobolus pararoseus, on human prostate cancer LNCaP and PC-3 cells via a mitochondrial signal pathway and the down-regulation of $A R$ expressiontt
}

\begin{abstract}
Chao Du, ${ }^{\text {ab }}$ Yahui Guo, ${ }^{a}$ Yuliang Cheng, ${ }^{a}$ Mei Han, ${ }^{\text {b } W e i g u o ~ Z h a n g ~}{ }^{* b}$ and He Qian*ac
In this work, we investigated the anti-cancer effect of torulene, a carotenoid from Sporidiobolus pararoseus, on androgen-sensitive/insensitive prostate cancer cells lines and found that torulene induced apoptosis at moderate cytotoxic concentrations in both cell lines. It was further demonstrated that the apoptosis induced by torulene was due to the modulation of Bcl-2 family members, resulting in decrease of mitochondria membrane potential and increase of the intracellular calcium concentration. Furthermore, its growth-inhibitory effects on LNCaP cells also showed a relationship with the down-regulation of AR and PSA expression. Therefore, the results indicated that a mitochondria-mediated pathway and the expression of AR might play essential roles in the apoptosis process induced by torulene in prostate cancer cells.
\end{abstract}

Received 4th October 2016 Accepted 29th November 2016

DOI: $10.1039 / \mathrm{c} 6 \mathrm{ra} 24721 \mathrm{k}$

www.rsc.org/advances best known one. Bcl-2 family proteins play important regulatory roles in mitochondrial pathway: Bax is a pro-apoptotic protein that can permeabilizes the mitochondrial outer membrane and lead to the loss of mitochondrial integrity and cell death, whereas Bcl-2 promotes the maintenance of mitochondrial integrity and prevents apoptotic cell death. ${ }^{11}$ Thus, novel alternatives that target both Bcl-2 family proteins and AR are attracting increasing interest.

Due to the deficiency and side effects of current therapies for prostate cancer, more and more patients turn to dietary supplements, including vitamins, herbal preparations and phytochemicals to control the risk of PCa ${ }^{6}$ Torulene, one of the most principal carotenoid in Sporidiobolus pararoseus, has 13 conjugated double bonds, and the differences of structure between it and lycopene are subtle. However, it has not been well-studied with respect to its bioactivity and nutritional function. ${ }^{12}$

The present study was carried out to evaluate the anti-cancer effect of torulene on androgen-sensitive human prostate cancer LNCaP cells and androgen-insensitive human prostate cancer PC-3 cells, as well as its relevant molecular mechanisms.

\section{Materials and methods}

\subsection{Cell culture and chemicals}

S. pararoseus (JD-2 CCTCC M 2010326) was obtained and characterized by our lab. Human prostate cancer cell lines LNCaP and PC-3 were obtained from Cell Bank of Chinese Academy of Sciences (Shanghai, China). The cells were cultured in RPMI1640 medium supplemented with $10 \%$ fetal bovine serum 
(FBS, Gibco, Carlsbad, CA, USA), $100 \mathrm{IU} \mathrm{mL}^{-1}$ penicillin, and $100 \mu \mathrm{g} \mathrm{mL}{ }^{-1}$ streptomycin in a humidified atmosphere of $95 \%$ air and $5 \% \mathrm{CO}_{2}$ at $37{ }^{\circ} \mathrm{C}$.

Torulene was isolated from the extracts of Sporidiobolus pararoseus and then purified according to the previous method..$^{13}$ The purity was above $96 \%$ as determined by High Performance Liquid Chromatography with UV detection at $450 \mathrm{~nm}$. The carotenoid was stored at $-80{ }^{\circ} \mathrm{C}$, and $10 \mathrm{mmol}$ stock solutions were freshly prepared with tetrahydrofuran (THF, Sigma) just before use. The final concentration of THF for all experiments and treatments (including the controls in which no drug was added) was maintained at the level less than $0.1 \%$. The concentration of THF less than $0.1 \%$ maintaining for $72 \mathrm{~h}$ was non-cytotoxic. ${ }^{14}$

Antibodies against Bcl-2 (\#2876), Bax (\#2272), AR(\#3202), PSA(\#2475) and $\beta$-actin (\#4967) were purchased from Cell Signaling Technology (CST, Danvers, MA, USA). ${ }^{9}$ 2-(4-Indophenyl)-3-(4-nitrophenyl)-5-(2,4-disulphophenyl)-2H-tetrazolium monosodium salt (WST-1) powder, 5,5',6,6'-tetrachloro-1,1', $3,3^{\prime}$ tetraethyl benzimidazolyl-carbocyanine iodide (JC-1), 2'-(4ethoxyphenyl)-5-(4-methyl-1-piperazinyl)-2,5'-bi-1 $H$-benzimidazole, trihydrochloride/3,8-diamino-5-[3-(diethylmethylammonio)propyl]6-phenylphenanthridinium diiodide (Hoechst 33342/PI) solution, and 4-(6-acetoxymethoxy-2,7-dichloro-3-oxo-9-xanthenyl)-4'-methyl$2,2^{\prime}$-(ethylenedioxy)dianiline- $N, N, N^{\prime}, N^{\prime}$-tetraacetic acid tetrakis(acetoxymethyl) ester (Fluo-3 AM) were purchased from Beyotime Institute of Biotechnology (Haimen, China). Other reagents were all obtained from Sinopharm Chemical Reagent Co., Ltd (Shanghai, China).

\subsection{Cell viability assay}

The inhibitory effects of torulene on the cancer cells were estimated via WST-1 assay. Cells were cultured in 96-well plates and exposed to different concentrations of torulene for $24 \mathrm{~h}$. Then the plates were incubated with WST-1 reagent for $3 \mathrm{~h}$ at $37^{\circ} \mathrm{C}$, and the inhibitory effects of the carotenoid on the cancer cells were measured by determining the absorbance at $450 \mathrm{~nm} .{ }^{15}$

\subsection{Morphological changes observed by staining with Hoechst 33342/PI}

Briefly, cells were seeded into a 6-well culture plate and then treated with the carotenoid at $30 \mu \mathrm{mol} \mathrm{L}^{-1}$ for $24 \mathrm{~h}$ and $48 \mathrm{~h}$, then harvested by trypsinization and centrifugation. After washing twice with cold phosphate buffered saline (PBS), a total of $1 \times 10^{5}$ cells were stained with Hoechst 33342/PI solution according to manufacturer's instructions and then morphologic changes of the cells were observed and photographed under a Laser Scanning Confocal Microscope (LSCM, Carl Zeiss AG, German). ${ }^{\mathbf{1 6}}$

\subsection{Evaluation of apoptosis and necrosis by annexin $\mathrm{V}$ and propidium iodide (PI) staining}

The extent of apoptosis was measured using an annexin V/ fluorescein isothiocyanate (FITC) apoptosis detection kit (Beyotimes Inc.). After being exposed to torulene (0, 10, 20 and $30 \mu \mathrm{mol} \mathrm{L}{ }^{-1}$ ) for $24 \mathrm{~h}$, the cells were collected, washed twice with PBS, gently resuspended in annexin $\mathrm{V}$ binding buffer, incubated with annexin V-FITC/PI in the dark for $15 \mathrm{~min}$, and analyzed with a FACS Calibur Flow Cytometer (Becton Dickinson, USA). ${ }^{10}$

\subsection{Mitochondrial membrane potential (MMP) assessment by JC-1 staining}

After treatment with the same process above, the mitochondrial membrane potential (MMP) of LNCaP and PC-3 cells was determined by JC-1 staining. Cells were firstly collected and resuspended in fresh medium. After the addition of $0.5 \mathrm{~mL}$ of JC-1 working solution, the cells were incubated in the dark at $37{ }^{\circ} \mathrm{C}$ for $20 \mathrm{~min}$. The staining solution was removed by

Table 1 The sequences of primers used for quantitative real-time PCR

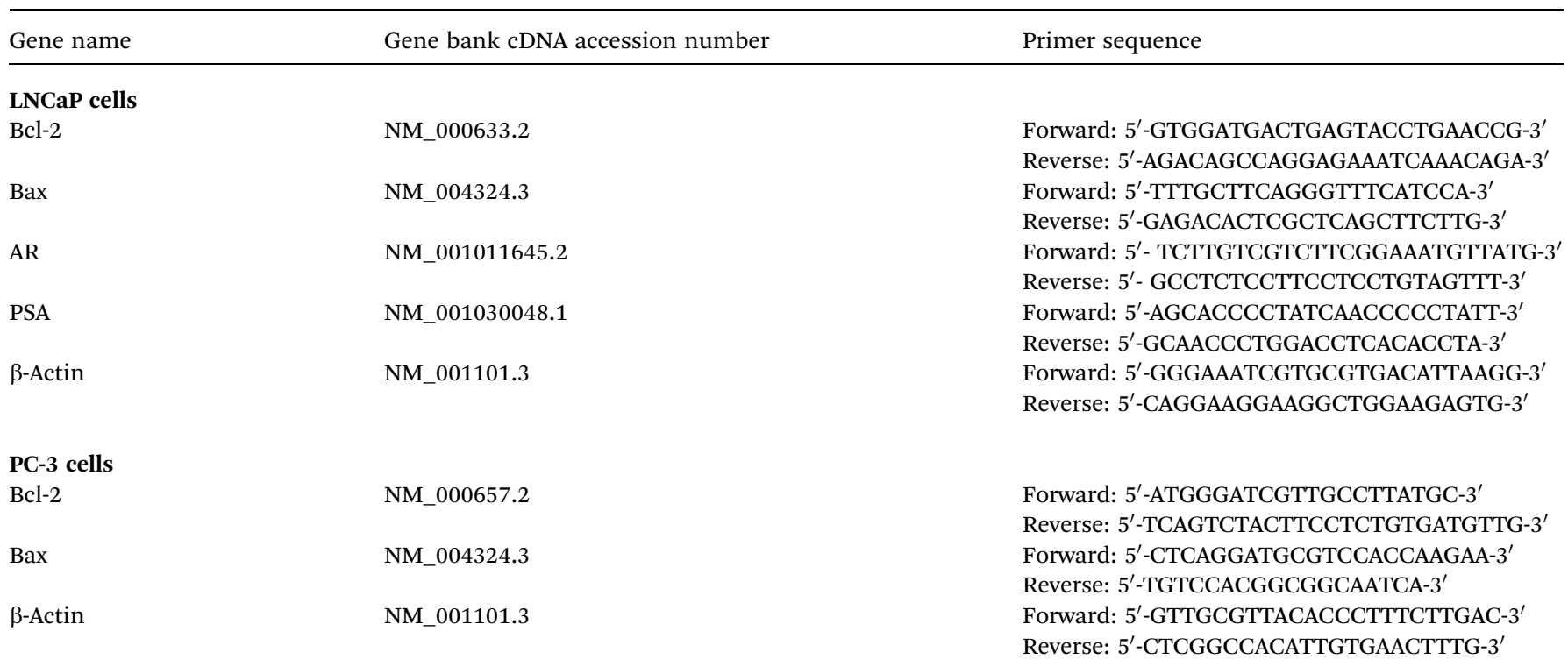


centrifugation and cells were washed twice with JC-1 staining buffer and analyzed using flow cytometry. ${ }^{\mathbf{1 6 , 1 7}}$

\subsection{Measurement and analysis of $\mathrm{Ca}^{2+}$ release}

The intracellular $\mathrm{Ca}^{2+}$ level in LNCaP and PC-3 cells was measured using the fluorescence $\mathrm{Ca}^{2+}$ indicator Fluo-3 AM. The cell culture and carotenoid-exposure is in the same way above. After $24 \mathrm{~h}$ treatment, the cells were collected, rinsed twice with PBS, and stained with Fluo-3 AM in darkness at room temperature for $30 \mathrm{~min}$. After staining, the cells were washed twice with PBS and incubated for another $10 \mathrm{~min}$ at $37{ }^{\circ} \mathrm{C}$ before fluorescence-intensity detection. ${ }^{18}$

\subsection{RNA extraction and quantitative real-time polymerase chain reaction (PCR)}

Total RNA was extracted from LNCaP and PC-3 cells of each sample using $1 \mathrm{~mL}$ of Trizol Reagent (Invitrogen, USA). Equal amounts of isolated RNA were reversely transcribed into cDNA using Revert Aid TM M-Mu LV Reverse Transcriptase (Thermo Scientific, Rockford, USA) according to the manufacturer's instructions. ${ }^{19}$ Real-time PCR was carried out on cDNA according to the SYBR Green method with an ABI 7900 Fast Real-Time PCR System (Applied Biosystems, Carlsbad, USA). The primers (Table 1) were synthesized by Generay Biotechnology (Shanghai, China). Quantitative real-time PCR was performed by initial incubation at $95{ }^{\circ} \mathrm{C}$ for $10 \mathrm{~min}$ and subsequent 40 cycles of a two-step PCR: annealing at $95{ }^{\circ} \mathrm{C}$ for $3 \mathrm{~s}$ and finally extension at $60^{\circ} \mathrm{C}$ for $30 \mathrm{~s}$. The threshold cycle $\left(C_{\mathrm{t}}\right)$ values of each sample were analyzed according to the $2^{-\Delta \Delta C_{\mathrm{t}}}$ data analysis method after normalizing to $\beta$-actin. ${ }^{20}$

\subsection{Western blot}

To evaluate the expression levels of various intracellular proteins related to apoptosis, LNCaP and PC-3 cells were treated with different concentrations of torulene $\left(0,10,20\right.$ and $\left.30 \mu \mathrm{mol} \mathrm{L}^{-1}\right)$ for $24 \mathrm{~h}$. Then total proteins from different groups were extracted with cell lysis buffer containing phenylmethanesulfonyl fluoride (PMSF). Lysates were centrifuged at $13200 \mathrm{rpm}$ for $15 \mathrm{~min}$ at $4{ }^{\circ} \mathrm{C}$ and protein concentrations were determined with an enhanced BCA Protein Assay Kit (Beyotime, China). Equal amounts of protein from each sample were loaded on 4-15\% sodium dodecyl sulfate (SDS)-polyacrylamide gel and then transferred to a polyvinylidene difluoride (PVDF) membrane. After blocking the nonspecific blinding with nonfat milk, the membranes were incubated overnight at $4{ }^{\circ} \mathrm{C}$ with rabbit polyclonal antibody against Bcl-2, Bax, AR, PSA and $\beta$-actin $(1$ : 1000). After washing for several times and conjugation with secondary antibodies, the membranes were incubated in the incubation solution added with enhanced chemiluminescence reagent (ECL Plus, Solarbio, Beijing, China) and then exposed to Chemiluminescence imaging analysis system (Protein Simple, California, USA). ${ }^{\mathbf{1 6}, 19}$

\subsection{Statistical analysis}

All assays were performed at least in triplicate independent experiments. Values were expressed as means \pm standard deviations (SD). Experimental data were analyzed by one-way analysis of variance (ANOVA) with Statistical Package for Social Science (SPSS) version 21.0. $p<0.05$ was considered to be statistically significant.

\section{Results}

\subsection{Effects of torulene on the viability of LNCaP and PC-3 cells}

Torulene treatment led to a dose-dependent decrease in cell viability of LNCaP and PC-3 cells, as indicated by the WST-1 assays, and PC-3 cells appeared to be slightly more sensitive than LNCaP to the treatment (Fig. 1). At $40 \mu \mathrm{mol} \mathrm{L}{ }^{-1}$ concentration, torulene decreased cell viability approx. 50\% on androgen-insensitive PC-3 cells, while the cell viability of androgen-sensitive LNCaP cells decrease approx. $15 \%$ vs. untreated control group. ${ }^{10}$

\subsection{Morphological changes caused by torulene}

In the optical images (Fig. 2A), the control cells were in the elongated spindle shape and the number of control cells gradually increased. However, after the treatment with torulene for $12 \mathrm{~h}$, the cells began to shrink and became round and then the number of cells decreased after $24 \mathrm{~h}$. After $48 \mathrm{~h}$ treatment, cell arrangement was loose and cells were not adhered well and finally most of cells were floated in the medium. ${ }^{15}$

The viable cells were bright blue, while the apoptotic cells were red as distinguished by Hoechst 33342/PI staining (Fig. 2B). After the exposures to $30 \mu \mathrm{mol} \mathrm{L} \mathrm{L}^{-1}$ torulene, the number of red cells gradually increased while there were few red cells in control group. ${ }^{21}$

\subsection{Torulene induced apoptotic cell death in LNCaP and PC- 3 cells}

As shown in Fig. 3, an obvious difference in apoptosis rate among different groups was observed after the treatment of

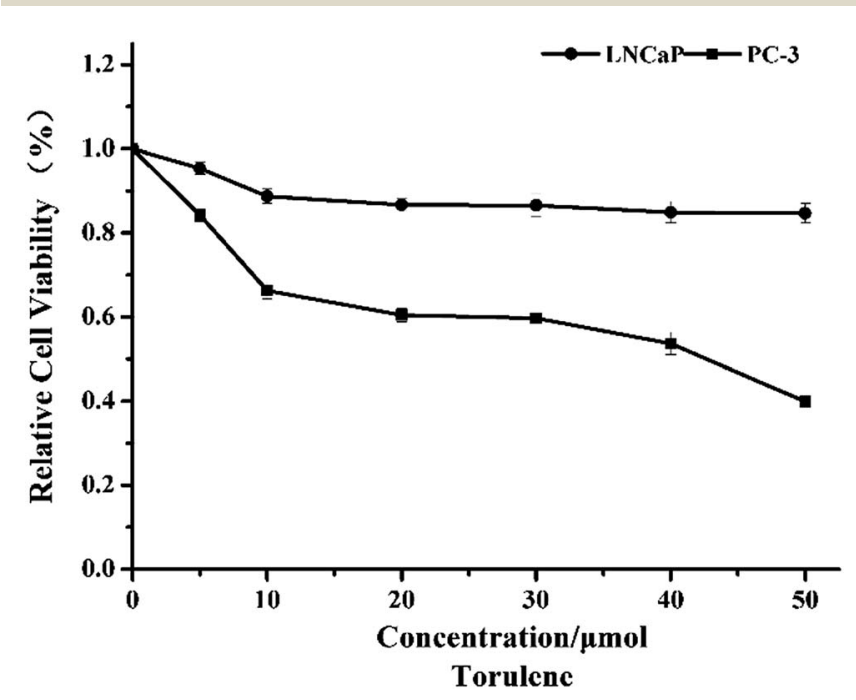

Fig. 1 Inhibitory effects of torulene on LNCaP and PC-3 cells. Cells were treated with the carotenoid at different concentrations for $24 \mathrm{~h}$, and the inhibition was detected by WST-1 assay. Data are expressed as mean $\pm \mathrm{SD}, n=5$. 

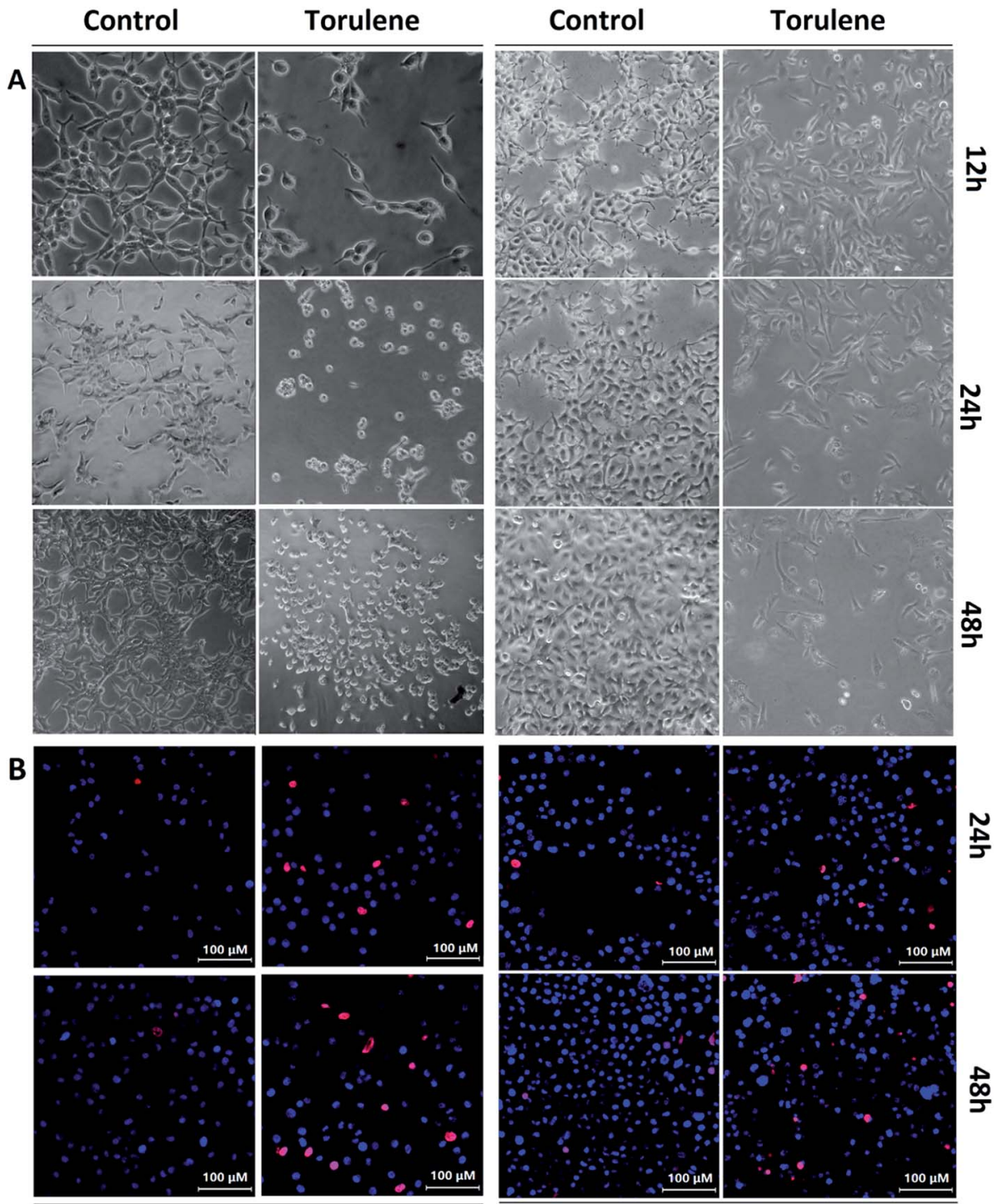

LNCaP

PC-3

Fig. 2 (A) Cell morphology alteration of LNCaP and PC-3 cells following torulene exposure. The cells were planted in 6-well plates were treated with torulene ( $30 \mu \mathrm{mol} \mathrm{L}^{-1}$ ) exposure for $12 \mathrm{~h}, 24 \mathrm{~h}$ and $48 \mathrm{~h}$, and then observed through an optical microscope (200x, final magnification). (B) Estimation of apoptosis using Hoechst 33342/PI staining on LNCaP and PC-3 cells. Torulene ( $\left.30 \mu \mathrm{mol} \mathrm{L}{ }^{-1}\right)$ was added to cancer cells for $24 \mathrm{~h}$ and $48 \mathrm{~h}$ following which cells were washed and stained with Hoechst 33342 (blue fluorescence) and PI (red fluorescence), and examined with a Laser Scanning Confocal Microscope. Figures are representative of three independent experiments.

torulene. After treatment for $24 \mathrm{~h}$ with $30 \mu \mathrm{mol} \mathrm{L}{ }^{-1}$ torulene, total fraction of apoptotic and necrosis cells increased from 5.04 (control) to 27.8 in LNCaP cells and from 5.92 (control) to 10.47 in PC-3 cells. These results suggested that torulene exerted better apoptotic effect on LNCaP cells. ${ }^{16}$

\subsection{Disruption of MMP and increase of intracellular $\mathrm{Ca}^{2+}$ in cells treated with torulene}

The results in Fig. 4A showed that treatment with torulene reduced the MMP in both cell lines. As monitored by JC-1 staining, in the cells treated with $30 \mu \mathrm{mol} \mathrm{L}{ }^{-1}$ torulene, the MMP was decreased by $12.57 \%$ in LNCaP cells and $9.04 \%$ in PC3 cells compared with the control group. ${ }^{\mathbf{1 6}}$
Calcium is a vital intracellular second messenger and involved in many different cell functions. ${ }^{21} \mathrm{~A}$ sustained increase in intracellular $\mathrm{Ca}^{2+}$ content was found in the all treatment groups when compared to the control groups (Fig. 4B). ${ }^{18}$ The result indicated that torulene had a stronger effect on the induction of apoptosis in LNCaP cells than PC-3 cells.

\subsection{Torulene decreased the expression of Bcl-2 and increased the expression of Bax}

Bcl-2 and Bax are two key influencing factors of cells' susceptibility to apoptosis. ${ }^{22}$ As shown in Fig. 5, quantitative PCR and western blot analysis revealed a significant decrease in Bcl-2 expression in both cells, whereas a significant increase in the 

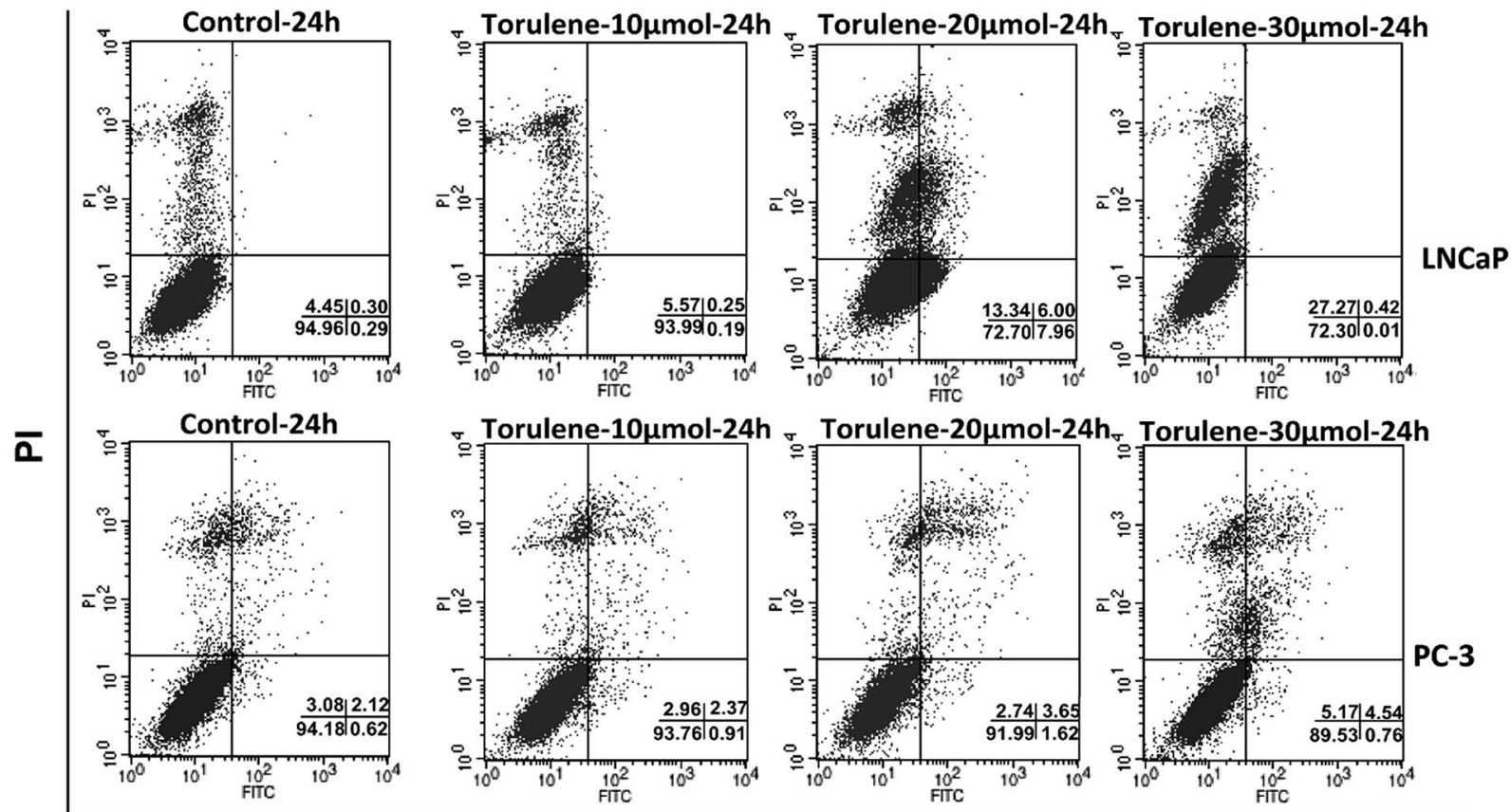

Annexin V-FITC

Fig. 3 Flow Cytometry analysis of apoptotic LNCaP and PC-3 cells using annexin V-PI staining. $2.5 \times 10^{5}$ cells were seeded into a 6 -well plate and treated with or without torulene $\left(10,20\right.$ and $\left.30 \mu \mathrm{mol} \mathrm{L}{ }^{-1}\right)$ for $24 \mathrm{~h}$. Annexin $\mathrm{V}$-PI staining was proceeded to determine apoptotic cell populations. Fluorescence signals from annexin $\mathrm{V}$-FITC and from PI are reported on $x$-axis and $y$-axis, respectively. Numbers shown in the lower right quadrant represent the percentage of viable (lower left), necrotic (upper left), early apoptotic (lower right), and late apoptotic (upper right) cells, $n=3$.

A

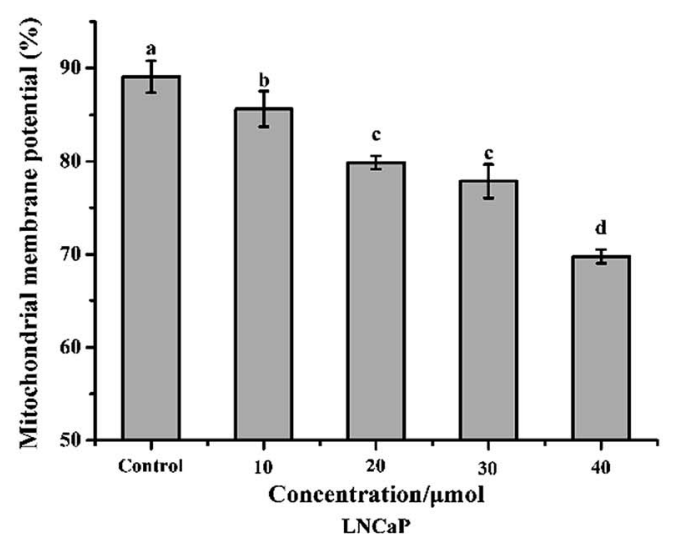

B

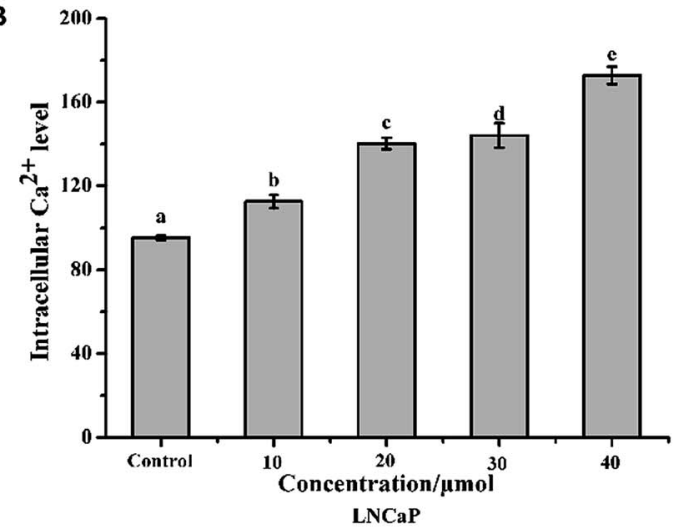

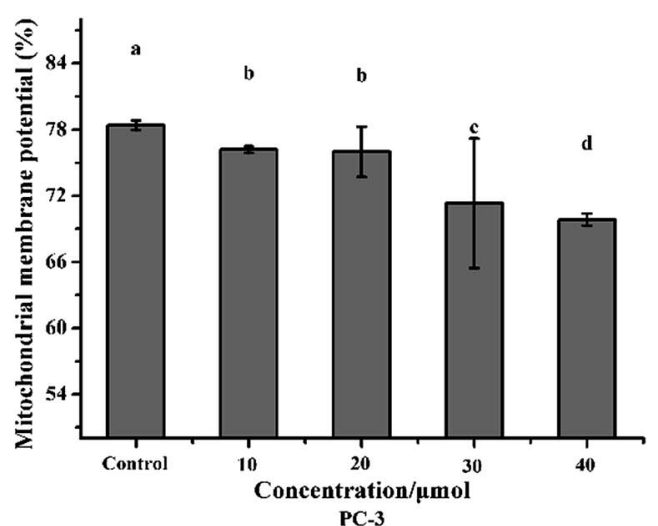

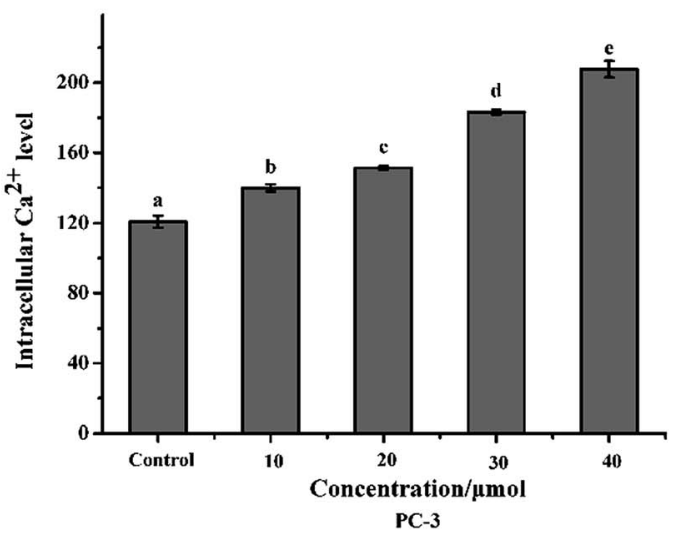

Fig. 4 (A) The mitochondrial membrane potential changes in LNCaP and PC-3 cells. (B) Changes in intracellular Ca ${ }^{2+}$ level of LNCaP and PC-3 cells. Cells were treated with or without torulene $\left(10,20,30\right.$, and $\left.40 \mu \mathrm{mol} \mathrm{L}{ }^{-1}\right)$ for $24 \mathrm{~h}$ and the results were assayed by flow cytometry. Data are expressed as mean $\pm \mathrm{SD}, n=3$. $p<0.05$ compared with control group. 

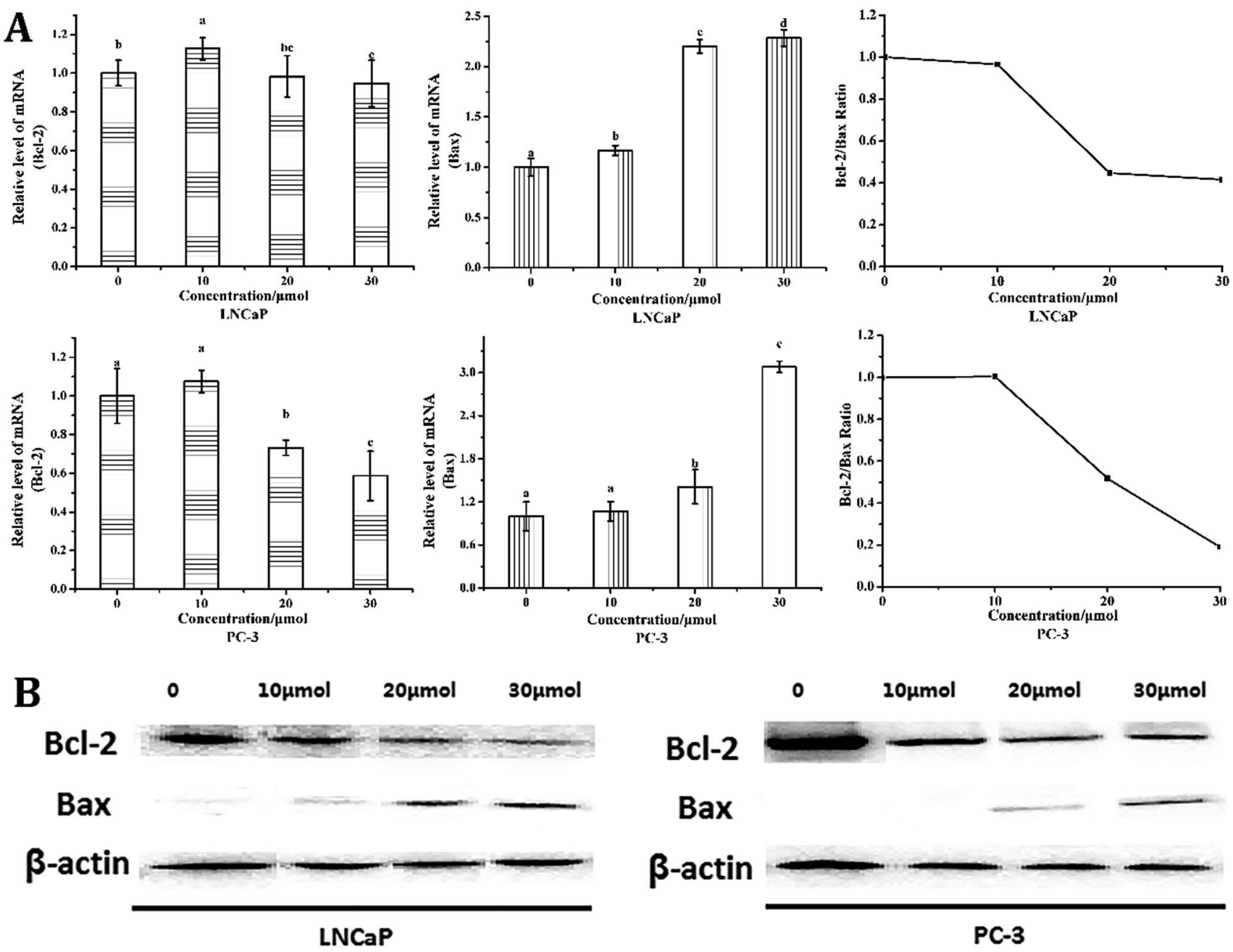

Fig. 5 (A) The mRNA expression of Bcl-2 and Bax and the ratio of Bcl-2/Bax in LNCaP and PC-3 cells. $\beta$-Actin was used as the control. Cancer cells were treated with or without torulene $\left(10,20\right.$ and $\left.30 \mu \mathrm{mol} \mathrm{L}^{-1}\right)$ for $24 \mathrm{~h}(p<0.05)$. (B) The effect of torulene on Bcl-2 protein expression was determined in LNCaP and PC-3 cells by western blot. Following $24 \mathrm{~h}$-torulene treatment, total proteins were isolated and separated in $12 \%$ SDS gel, blotted in PVDF membrane and applied with Bcl-2 and Bax antibodies. $\beta$-Actin was used as a loading control.

expression of Bax was observed, indicating that the Bcl-2/Bax ratio decreased significantly. What's more, the mRNA expression of Bcl-2 was decreased from 1.00 in control group to 0.94and 0.59-fold, whereas the expression of Bax increased from 1.00 in control group to 2.29- and 3.08-fold after $24 \mathrm{~h}$ treatment with $30 \mu \mathrm{mol} \mathrm{L}{ }^{-1}$ torulene in LNCaP and PC-3 cells (Fig. 5A), respectively. ${ }^{10,16}$

\subsection{Torulene increase the expression of AR and PSA}

Downregulation of $\mathrm{AR}$ inhibits the proliferation of LNCaP cells. $^{22}$ To investigate whether the induction of apoptosis by torulene was due to the downregulation of AR, cells were subjected to western blot and quantitative PCR analysis. As shown in Fig. 6, torulene significantly decreased AR and PSA protein and mRNA expression in a dose-dependent manner in LNCaP cells. Torulene treatment at $30 \mu \mathrm{mol} \mathrm{\textrm {L } ^ { - 1 }}$ for $24 \mathrm{~h}$ downregulated AR by $29 \%$, whereas PSA was down-regulated by $28 \%$ compared with the control, respectively.

\section{Discussion}

Prostatic adenocarcinoma is the most frequently diagnosed malignancy and the second cause of cancer deaths amongst men, and it development process can be divided into two distinct operationally divisible androgen-sensitive and androgen-insensitive stages. ${ }^{23}$ Thus, exploration of new chemicals for treatment of androgen-sensitive and androgeninsensitive prostate cancer is necessary. In the present study, LNCaP and PC-3 cells have been used to study the effects of torulene on the androgen-sensitive and androgen-insensitive human prostate cancer cells. ${ }^{23}$

Torulene is one of the most principal carotenoids in Sporidiobolus pararoseus and the differences of structure between torulene and lycopene are subtle. Galano et al. reported that torulene owns better free-radical scavenging activity than $\beta$ carotene towards the $\mathrm{OOH}$ radical $^{24}$ and exerted more efficient electron-transfer reactions than lycopene, which has been recognized as one of the most reactive carotenoids towards free 

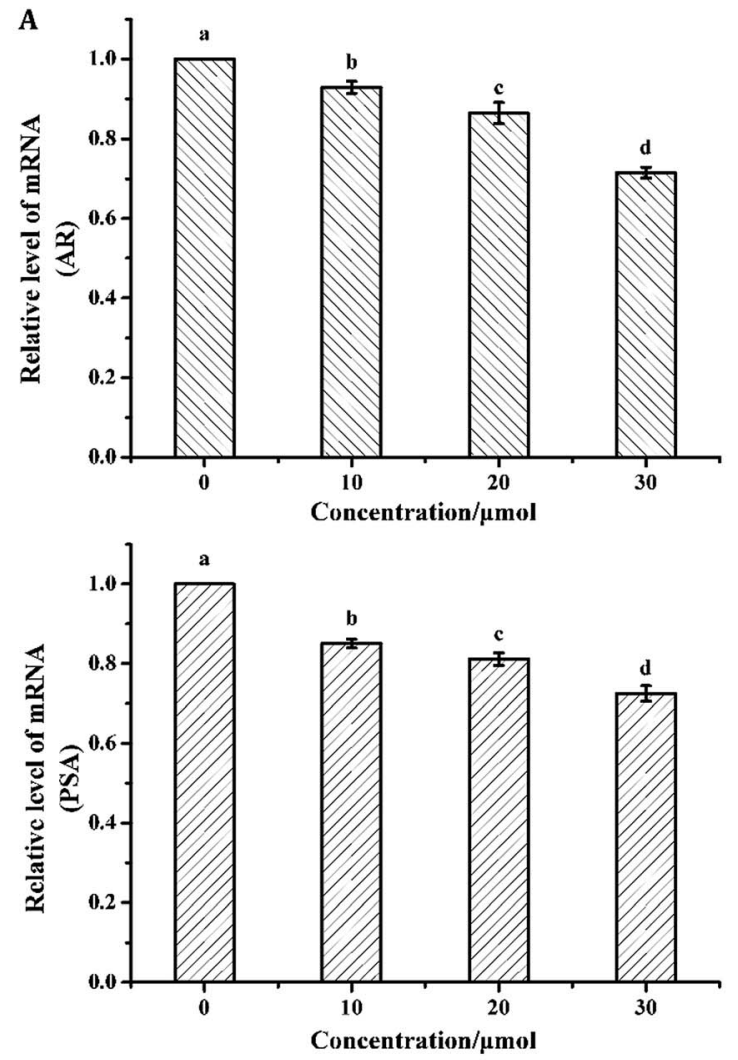

B

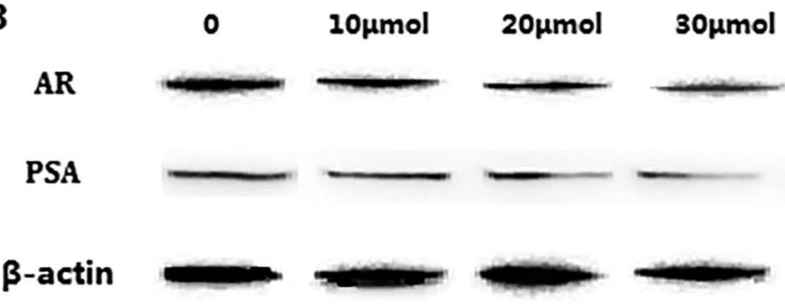

Fig. 6 (A) The mRNA expression of AR and PSA in LNCaP cells. $\beta$-Actin was used as the control. Cancer cells were treated with or without torulene $\left(10,20\right.$ and $\left.30 \mu \mathrm{mol} \mathrm{L} L^{-1}\right)$ for $24 \mathrm{~h}(p<0.05)$. (B) The protein expression of AR and PSA in LNCaP cells. The effect of torulene on AR and PSA protein expression was determined in $\mathrm{LNCaP}$ cells by western blot. Following $24 \mathrm{~h}$-torulene treatment, total proteins were isolated and separated in $12 \%$ SDS gel, blotted in PVDF membrane and applied with AR and PSA antibodies. $\beta$-Actin was used as a loading control.

radicals. ${ }^{25,26}$ However, the effect of torulene on human prostate carcinoma was still unknown. In the present study, we confirmed that torulene inhibited growth and induced apoptosis in androgen-sensitive LNCaP and androgeninsensitive PC-3 prostate cancer cells. When the exposure concentration increased, the cellular viability decreased in both groups. Moreover, according to WST-1 assay, PC-3 cells were more sensitive against torulene treatment compared to LNCaP cells. $^{18,27}$ Cell morphology plays vital roles in diverse cellular processes, including cell growth, motility, proliferation, and division. ${ }^{21}$ To investigate the mechanism induced by the carotenoids, the changes in cell morphology were also observed and the observation results were consistent with that of viability analysis.
In the explorations of cell death mechanism, flow cytometric analysis of annexin V-FITC/PI-labeled cells, MMP and intracellular $\mathrm{Ca}^{2+}$ levels had been carried out. ${ }^{27,28}$ The decrease in MMP is the earliest intracellular event before the apoptosis caused by the mitochondria-mediated death pathway, so the decline of MMP is considered as a symbolic event of early cellular apoptosis. ${ }^{16}$ In this assay, both groups showed a significant $(p<0.05)$ decrease in MMP when treated with carotenoids compared to the control group. This result demonstrated the early damage was happened to MMP, which may further activate the intrinsic pathway of apoptosis.

Moreover, intracellular $\mathrm{Ca}^{2+}$ is an important intracellular secondary messenger, which regulates lots of cellular processes including cell growth, proliferation, and signal transduction. The abnormal rise of cytosol $\mathrm{Ca}^{2+}$ is considered to be responsible for a series of disturbances in cells. Disturbance of $\mathrm{Ca}^{2+}$ balance will trigger diverse abnormal cellular processes, even apoptosis or necrosis. ${ }^{21}$ In our experiments, after the treatment with torulene, there was a rapid rise of cytosol $\mathrm{Ca}^{2+}$ level, which might be caused by the $\mathrm{Ca}^{2+}$ release from endoplasmic reticulum and mitochondria in the apoptotic process. These results indicate that carotenoids may interfere with the cellular maintenance functions of LNCaP and PC-3 cells and lead to apoptosis. A similar result was obtained by Hua Jin et al. ${ }^{21}$ in the hepatocellular carcinoma cell line (HepG2), suggesting that the induced alteration of cellular maintenance might be partly responsible for apoptosis.

Pro-apoptotic protein Bax and anti-apoptotic protein Bcl-2 also play significant roles in mediating the cell apoptosis. ${ }^{11}$ In mitochondrial pathway, the release of cytochrome $\mathrm{c}$ is regulated by Bcl-2 family proteins, which is inhibited by anti-apoptotic members of the Bcl-2 family of protein and stimulated by proapoptotic members, such as Bax. In this paper, the expression of anti-apoptotic Bcl-2 protein was inhibited, whereas the expression of pro-apoptotic Bax protein was enhanced steadily with the increase of the carotenoids' concentrations. ${ }^{16}$ The changes of the protein expression levels of Bcl-2 and Bax were almost parallel to that of their mRNA expression according to the analysis results of quantitative real-time PCR and western blot. The ratio of Bcl-2/Bax plays an important role in cell apoptosis or survival. In our study, torulene treatment caused the decrease of the ratio of Bcl-2/Bax in both LNCaP and PC-3 cells. The result was much more effective toward androgeninsensitive PC-3 cells, which can explain the susceptivity difference to torulene in PCa cells with different androgen sensitivity. To sum up, these results confirmed that torulene induced the prostate cancer cells apoptosis by inhibiting Bcl-2 and activating Bax, which suggested that the intrinsic pathway might be activated directly. ${ }^{\mathbf{1 1}}$ That is to say, the apoptosis of LNCaP and PC-3 cells treated with torulene was induced by activating the mitochondrial pathway.

AR is expressed in almost all prostate cancers, and its expression plays an important role in the development and progression of prostate cancer. Therefore, downregulation of AR, which inhibits PCa cell proliferation, is currently used as an effective strategy to treat prostate cancer. ${ }^{8}$ PSA, a key AR target gene, is a common biomarker for PCa screening and one of the 
most important indicators of treatment efficacy. In this paper, we investigated whether AR and PSA are molecular targets of torulene on androgen-sensitive LNCaP cells. Our results showed that torulene down-regulated the protein and mRNA expression of AR and PSA in a dose-sensitive manner in LNCaP cells. These findings suggested that torulene may exert its anti-proliferative effects through both activating the mitochondrial pathway and inhibiting the expression of AR and PSA in androgen-sensitive PCa cells.

Although androgen-sensitive PCa cells appeared to be less sensitive than androgen-insensitive ones to the treatment according to WST-1 assay (Fig. 1), torulene induced more apoptosis in LNCaP cells as analyzed by annexin V and PI double staining (Fig. 3). WST-1 assay was usually used to evaluate the proliferation of the cells rather than to distinguish the apoptosis cells to the normal ones. ${ }^{10}$ Thus, we presume that the mechanism related to the inhibitory effect of torulene on androgen-sensitive LNCaP cells and androgen-insensitive PC-3 cells was different, other pathway was involved in besides mitochondria mediated apoptosis.

In summary, our data indicated that the inhibition of torulene on proliferation of LNCaP and PC-3 cells was associated with the inducement of apoptosis, which partly resulted from the loss of MMP and the accumulation of intracellular $\mathrm{Ca}^{2+}$. Over expressions of Bax and the decreased expression of Bcl-2 induced by torulene also contributed to the programmed cell death of prostate cancer cells. Furthermore, the apoptotic effect of torulene on LNCaP cells had relationship with the down-regulation of the expression of AR and PSA as well. These results provide a potential molecular mechanism for torulene-induced apoptosis on LNCaP and PC-3 prostate cancer cells and suggest that torulene may process a health benefit for humans prostate. However, further studies on other signaling pathways and deep molecular mechanisms still require investigation.

\section{Conflict of interest}

The authors declare that they have no competing interests.

\section{Acknowledgements}

This study was supported by National Key Technology R \& D Program in the 12th Five year Plan of China (No. 2015BAD16B01, No. 2014BAD04B03), program of Collaborative innovation center of food safety and quality control in Jiangsu Province.

\section{References}

1 N. A. Ford, A. C. Elsen, K. Zuniga, B. L. Lindshield and J. W. Erdman Jr, Lycopene and apo-12'-lycopenal reduce cell proliferation and alter cell cycle progression in human prostate cancer cells, Nutr. Cancer, 2011, 63(2), 256-263.

2 L. Tang, T. Jin, X. Zeng and J.-S. Wang, Lycopene Inhibits the Growth of Human Androgen-Independent Prostate Cancer Cells In Vitro and in BALB/c Nude Mice, J. Nutr., 2005, 135(2), 287-290.
3 Y. Zhang, D. Ouyang, L. Xu, X. He, L. Zeng, J. Cai and S. Ren, Autophagy is differentially induced in prostate cancer LNCaP, DU145 and PC-3 cells via distinct splicing profiles of ATG5, Autophagy, 2013, 9(1), 20-32.

4 H. Zhao, C. Zhu, C. Qin, T. Tao, J. Li, G. Cheng, P. Li, Q. Cao, X. Meng, X. Ju, P. Shao, L. Hua, M. Gu and C. Yin, Fenofibrate down-regulates the expressions of androgen receptor (AR) and AR target genes and induces oxidative stress in the prostate cancer cell line LNCaP, Biochem. Biophys. Res. Commun., 2013, 432(2), 320-325.

5 Y. Tang, B. Parmakhtiar, A. R. Simoneau, J. Xie, J. Fruehau, M. Lilly and X. Zi, Lycopene Enhances Docetaxel's Effect in Castration-Resistant Prostate Cancer Associated with Insulin-like Growth Factor I Receptor Levels, Neoplasia, 2011, 13(2), 108-119.

6 S. Murthy, M. Wu, V. U. Bai, Z. Hou, M. Menon, E. R. Barrack, G. Sahn-Ho Kim and P.-V. Reddy, Role of androgen receptor in progression of LNCaP prostate cancer cells from G1 to $\mathrm{S}$ phase, PLoS One, 2013, 8(2), 1-10.

7 N. I. Ivanov, S. P. Cowell, P. Brown, P. S. Rennie, E. S. Guns and M. E. Cox, Lycopene differentially induces quiescence and apoptosis in androgen-responsive and -independent prostate cancer cell lines, Clin. Nutr., 2007, 26(2), 252-263.

8 L. Kong, Q. Yuan, H. Zhu, Y. Li, Q. Guo, Q. Wang, X. Bi and $\mathrm{X}$. Gao, The suppression of prostate LNCaP cancer cells growth by selenium nanoparticles through Akt/Mdm2/AR controlled apoptosis, Biomaterials, 2011, 32(27), 6515-6522.

9 C. Feng, L. Zhou, T. Yu, G. Xu, H. Tian, J. Xu, H. Xu and K. Luo, A new anticancer compound, oblongifolin C, inhibits tumor growth and promotes apoptosis in HeLa cells through Bax activation, Int. J. Cancer, 2012, 131(6), 1445-1454.

10 T. Zhang, H. Yu, G. Dong, L. Cai and Y. Bai, Chamaejasmine arrests cell cycle, induces apoptosis and inhibits nuclear NFkappaB translocation in the human breast cancer cell line MDA-MB-231, Molecules, 2013, 18(1), 845-858.

11 T. Shen, L. Zhang, Y. Wang, P. Fan, X. Wang, Z. Lin and H. Lou, Steroids from Commiphora mukul display antiproliferative effect against human prostate cancer PC3 cells via induction of apoptosis, Bioorg. Med. Chem. Lett., 2012, 22(14), 4801-4806.

12 E. D. Simova, G. I. Frengova and D. M. Beshkova, Synthesis of carotenoids by Rhodotorula rubra GED8 co-cultured with yogurt starter cultures in whey ultrafiltrate, J. Ind. Microbiol. Biotechnol., 2004, 31(3), 115-121.

13 Q. Shi, H. Wang, C. Du, W. Zhang and H. Qian, Tentative Identification of Torulene Cis/trans Geometrical Isomers isolated from Sporidiobolus pararoseus by HighPerformance Liquid Chromatography-Diode Array Detection-Mass Spectrometry and Preparation by Column Chromatography, Anal. Sci., 2013, 29(10), 997-1002.

14 M. Ono, T. Higuchi, M. Takeshima, C. Chen and S. Nakano, Antiproliferative and apoptosis-inducing activity of curcumin against human gallbladder adenocarcinoma cells, Anticancer Res., 2013, 33(5), 1861-1866.

15 H. Wang, T. Wen, H. Cheng and K. Wang, Different effects of histone deacetylase inhibitors nicotinamide and 
trichostatin A (TSA) in C17.2 neural stem cells, J. Neural Transm., 2012, 119(11), 1307-1315.

16 F. Ding, Q. Wu, Z. Shao, F. Gao, S. Yang and L. Xiong, Role of mitochondrial pathway in compression-induced apoptosis of nucleus pulposus cells, Apoptosis, 2012, 17(6), 579-590.

$17 \mathrm{X} . \mathrm{Su}, \mathrm{X}$. Zheng and J. Ni, Lanthanum citrate induces anoikis of Hela cells, Cancer Lett., 2009, 285(2), 200-209.

18 X. Li, C. Jing, X. Zang, S. Yang and J. Wang, Toxic cytological alteration and mitochondrial dysfunction in PC12 cells induced by 1-octyl-3-methylimidazolium chloride, Toxicol. In Vitro, 2012, 26(7), 1087-1092.

19 J. Han, Z. Tao, S. Chen, Y. Kong and B. Xiao, Adenovirusmediated transfer of tris-shRNAs induced apoptosis of nasopharyngeal carcinoma cell in vitro and in vivo, Cancer Lett, 2011, 309(2), 162-169.

20 Y. Wei, Y. Xu, X. Han, Y. Qi, L. Xu, Y. Xu, L. Yin, H. Sun, K. Liu and J. Peng, Anti-cancer effects of dioscin on three kinds of human lung cancer cell lines through inducing DNA damage and activating mitochondrial signal pathway, Food Chem. Toxicol., 2013, 59, 118-128.

21 H. Jin, P. Yang, J. Cai, J. Wang and M. Liu, Photothermal effects of folate-conjugated $\mathrm{Au}$ nanorods on HepG2 cells, Appl. Microbiol. Biotechnol., 2012, 94(5), 1199-1208.

22 X. Lu, S. Dong, N. Zhang, Y. Hu and B. Meng, Involvement of GPR12 in the regulation of cell proliferation and survival, Mol. Cell. Biochem., 2012, 366(1-2), 101-110.
23 D. N. Gunadharini, P. Elumalai, R. Arunkumar, K. Senthilkumar and J. Arunakaran, Induction of apoptosis and inhibition of PI3K/Akt pathway in PC-3 and LNCaP prostate cancer cells by ethanolic neem leaf extract, $J$. Ethnopharmacol., 2011, 134(3), 644-650.

24 A. Galano, M. Francisco-Marquez and J. R. Alvarez-Idaboy, Canolol: a promising chemical agent against oxidative stress, J. Phys. Chem. B, 2011, 115(26), 8590-8596.

25 T. Lenzer, K. Oum, J. Seehusen and M. T. Seidel, Transient Lens Spectroscopy of Ultrafast Internal Conversion Processes in Citranaxanthin, J. Phys. Chem. A, 2006, 110(9), 3159-3164.

26 A. Galano, Influence of Silicon Defects on the Adsorption of Thiophene-like Compounds on Polycyclic Aromatic Hydrocarbons: A Theoretical Study Using Thiophene + Coronene as the Simplest Model, J. Phys. Chem. A, 2007, 111(9), 1677-1682.

27 E. D. Arisan, P. Obakan, A. Coker-Gürkan, A. Calcabrini, E. Agostinelli and N. P. Unsal, CDK Inhibitors Induce Mitochondria-mediated Apoptosis Through the Activation of Polyamine Catabolic Pathway in LNCaP, DU145 and PC3 Prostate Cancer Cells, Curr. Pharm. Des., 2014, 20(2), 180188.

28 A. Mun, S. Lee, G. Kim, H. Kang, J. Kim and S. Kim, Fluoxetine-induced Apoptosis in Hepatocellular Carcinoma Cells, Anticancer Res., 2013, 33(9), 3691-3697. 